\title{
Aplikasi Pengenalan Bahasa Arab dan Inggris untuk Anak-Anak Berbasis Android
}

\author{
Hilman Septian ${ }^{1}$, Eka Wahyu Hidayat ${ }^{2}$, Alam Rahmatulloh ${ }^{3}$ \\ 1,2,3 Teknik Informatika, Universitas Siliwangi \\ 1hilman.septian@gmail.com, ${ }^{2}$ ekawahyu@unsil.ac.id, ${ }^{3}$ alam@unsil.ac.id
}

\begin{abstract}
Language is the most important communication tool for humans because language serves as a means of transmitting messages from one person to another. One of the most popular languages among Indonesians is English and Arabic. Learning Arabic and English is done by face to face with teachers at school or in science assemblies, in addition to memorizing Arabic and English can be done by reading a book or a dictionary language. However, for children of early age can not reading well. These ways of learning still have limitations of which there must be a teaching staff or teachers, dictionary books and children should be able to read well. With the technology, one of them Android can help the learning process so that learning can be changed into digital form with the hope of learning can be more practical. This method becomes one of the alternatives as a medium of learning that can motivate children to be more eager in learning the language. In this research will make an introduction application of English and Arabic with multimedia product engineering approach according to Luther-Sutopo concept with concept, design, collecting, assembly, testing, and distribution. This research produces a multimedia product introduction of Arabic and English based on Android. Based on the alpha test it is found that functionally appropriate and from the beta test results obtained $87 \%$ value, which means multimedia products introduction of Arabic and English language in the interpretation of "Very Eligible" by the user and can be distributed.
\end{abstract}

Keywords- Android, Arabic, English, Multimedia, Smartphone

\begin{abstract}
Abstrak- Bahasa adalah alat komunikasi yang paling penting bagi manusia, karena bahasa berfungsi sebagai alat penyampai pesan dari seseorang kepada orang lain. Salah satu bahasa yang popular di kalangan masyarakat Indonesia adalah bahasa Inggris dan bahasa Arab. Pembelajaran bahasa Arab dan bahasa Inggris dilakukan dengan cara tatap muka langsung dengan guru di sekolah atau di majelis ilmu, selain itu untuk menghafal bahasa Arab dan bahasa Inggris bisa dilakukan dengan membaca buku atau kamus bahasa. Akan tetapi untuk anak-anak usia dini belum bisa membaca dengan baik. Dengan cara pembelajaran tersebut masih memiliki keterbatasan diantaranya harus ada staf pengajar atau guru, buku kamus dan anak harus bisa membaca dengan baik. Dengan adanya teknologi salah satunya Android dapat membantu proses pembelajaran sehingga pembelajaran dapat dirubah kedalam bentuk digital dengan harapan pembelajaran bisa menjadi lebih praktis. Cara ini menjadi salah satu alternative sebagai media pembelajaran yang dapat memotivasi anak-anak agar lebih bersemangat dalam mempelajari bahasa. Pada penelitian ini akan membuat aplikasi pengenalan bahasa Inggris dan bahasa Arab dengan pendekatan rekayasa produk multimedia menurut konsep Luther-Sutopo dengan tahapan concept, design, material collecting, assembly, testing dan distribution. Penelitian ini menghasilkan sebuah produk multimedia pengenalan bahasa Arab dan bahasa Inggris berbasis Android. Berdasarkan pengujian alpha didapat bahwa secara fungsional sudah sesuai dan dari hasil pengujian beta didapat nilai $87 \%$ yang artinya produk multimedia pengenalan bahasa Arab dan Inggris di interpretasi "Sangat Layak" oleh pengguna dan dapat di distribusikan.
\end{abstract}

Kata kunci- Android, Bahasa Arab, Bahasa Inggris, Multimedia, Smartphone

\section{PENDAHULUAN}

Teknologi informasi kini telah menyentuh hampir semua aspek kehidupan, bahkan dalam hal pengajaran dan khususnya dalam bidang pembelajaran bahasa. Pada umumnya bahasa memiliki peranan sebagai alat komunikasi, karena bahasa berfungsi sebagai alat penyampai pesan dari seseorang kepada orang lain. Pada era globalisasi, peran bahasa semakin berkembang menjadi pertukaran informasi antar negara tentang budaya, teknologi dan bidang keilmuan lainnya. Perkembangan bahasa asing sekarang semakin berkembang pesat, bahasa Inggris dan bahasa Arab juga merupakan bahasa yang banyak juga digunakan dan diajarkan kepada anak-anak.
Bahasa Arab dan Inggris merupakan ilmu yang mengembangkan keterampilan berkomunikasi lisan dan tulisan. Bahasa Arab dan Inggris yang diajarkan di sekolah berfungsi sebagai bahasa agama dan ilmu pengetahuan, disamping sebagai alat komunikasi. Pembelajaran bahasa Arab dan bahasa Inggris dilakukan dengan cara tatap muka langsung dengan guru di sekolah selain itu, untuk menghafal bahasa Arab dan bahasa Inggris bisa dilakukan dengan membaca buku atau kamus bahasa. Akan tetapi untuk anak-anak usia dini belum bisa membaca dengan baik. Cara pembelajaran tersebut masih memiliki keterbatasan diantaranya harus ada staf pengajar atau guru, buku kamus dan anak harus bisa membaca dengan baik. Pada era digital sekarang ini penggunaan sistem operasi salah satunya teknologi android yang 
paling banyak digunakan, baik pada smartphone maupun tablet [1]. Dalam penelitian ini akan dilakukan upaya untuk menerapkan acara pembelajaran bahasa dalam bentuk digital berbasis multimedia pada sistem operasi android yang dapat memotivasi anak-anak agar lebih bersemangat dalam mempelajari Bahasa dan penggunaan smartphone yang lebih portable.

Adapun batasan masalah pada penelitian ini adalah:

1. Aplikasi ini mengambil sumber utama dalam buku "KAMUS 3 BAHASA". Yudistira Ikranegara. Penerbit Lingkar Media.

2. Hasil terjemahan hanya dapat ditampilkan dalam bentuk kata bukan kalimat.

3. Aplikasi ini hanya berisi delapan materi yaitu alam semesta, alat tulis, anggota tubuh, angka, buah-buahan, jenis kendaraan, dan nama hari.

4. Aplikasi ini hanya menggunakan bahasa Indonesia sebagai bahasa default.

Adapun tujuan dari penelitian ini adalah:

Tujuan dari penelitian ini adalah membuat aplikasi pengenalan bahasa Arab dan Inggris untuk anak-anak berbasis multimedia yang dapat berjalan atau digunakan pada perangkat android.

Adapun manfaat yang didapat dari penelitian yang dilakukan adalah:

Manfaat dari penelitian ini adalah menjadi salah satu alternatif media pembelajaran bahasa Arab dan Inggris mengunakan konsep multimedia dengan smartphone berbasis android dan untuk memotivasi anak-anak lebih bersemangat dalam mempelajari bahasa.

\section{LANDASAN TEORI}

\section{A. MEDIA PEMBELAJARAN}

Media pembelajaran adalah segala sesuatu yang dapat menyampaikan dan menyalurkan pesan dari sumber secara terencana sehingga tercipta lingkungan belajar yang kondusif dimana penerimanya dapat melakukan proses belajar secara efisien dan efektif [2]. Sementara pendapat dari Gagne dan Briggs [3] media pembelajaran adalah alat atau tools yang digunakan untuk menyampaikan isi materi pembelajaran yang beberapa diantaranya dalam bentuk fisik buku, tape recorder, video camera, video recorder yang menghasilkan gambar dan suara seperti televisi dan komputer. Dengan kata lain, media adalah komponen belajar atau alat yang mengandung materi intruksional yang dapat menarik minat siswa untuk belajar.

\section{B. MULTIMEDIA}

Multimedia adalah hasil kombinasi atau perpaduan dari teks, gambar, seni grafik, suara, animasi dan elemenelemen video yang dimanipulasi dan dibentuk secara digital. Tampilan dan hasil dari proyek multimedia harus menyenangkan, estetis, mengundang minat dan mengikat.
Dengan kata lain proyek harus memuat kejelasan secara visual, hanya dengan menggunakan elemen-elemen multimedia yang mendukung pesan keseluruhan dari program [4].

\section{REKAYASA PERANGKAT LUNAK}

Rekayasa perangkat lunak adalah disiplin ilmu yang membahas tahapan-tahapan dari setiap aspek produksi perangkat lunak, mulai dari menganalisa apa yang dibutuhkan pengguna, menentukan spesifikasi kebutuhan pengguna, tampilan desain, pengkodean, testing atau pengujian perangkat lunak sampai dengan pemeliharaan atau perbaikan sistem setelah digunakan [5].

\section{REKAYASA PERANGKAT \\ MULTIMEDIA}

Dari beberapa metode pengembangan perangkat multimedia yang ada diantaranya metode Godfrey, Villamil-Molina, Luther, Sherwood-Rout dan Vaughan. Metode luther dirasa paling cocok untuk penelitian ini dikarenakan metode ini tidak membentuk organisasi (bisa dikerjakan mandiri), penamaan setiap tahapan dengan proses pengerjaannya sesuai dan metode ini tidak membahas tentang pembiayaan pengembangan perangkat lunak multimedia.

Tahapan dari metode Luther-Sutopo adalah sebagai berikut:

1. Concept, adalah tahapan untuk menentukan tujuan, mengidentifikasi pengguna, jenis produk, dasar aturan, ukuran dan target.

2. Design, adalah tahapan pembuatan spesifikasi mengenai arsitektur program, style, antarmuka, dan elemen-elemen pendukung.

3. Material Collecting, adalah tahapan pengumpulan elemen multimedia seperti materi atau bahan-bahan apa saja yang sesuai dengan kebutuhan produk multimedia yang akan dibuat.

4. Assembly, adalah tahapan penggabungan semua material ke dalam proyek berdasarkan pada tahap design.

5. Testing, adalah tahapan pengujian produk yang telah melalui tahap assembly untuk melihat kemungkinan adanya kesalahan. Alpha test dilakukan oleh pembuat atau pengembang aplikasi, setelah itu akan dilakukan pengujian beta test yang melibatkan pengguna akhir.

6. Distribution, adalah tahap dimana produk dikemas dalam suatu media penyimpanan untuk didistribusikan kepada pengguna akhir atau klien.

Kelebihan metode dari versi Luther-Sutopo ini terdapat pada tahapan material collecting yang menyarankan untuk mempersiapkan elemen-elemen multimedia yang dibutuhkan sebelum dilakukan penggabungan keseluruhan material yang di butuhkan.

\section{E. ANDROID}

Android merupakan OS (Operating System) Mobile berbasis linux yang tumbuh di tengah sistem operasi 
lainnya yang berkembang pada jaman sekarang ini [6]. Sistem operasi lain diantaranya seperti Windows Mobile, iOS, Symbian, dan masih banyak lagi. Akan tetapi sistem operasi yang sekarang ini cenderung mengutamakan aplikasi inti tanpa melihat potensi lain yang cukup besar dari aplikasi-aplikasi pihak ketiga. [7].

\section{METODOLOGI}

Metode yang digunakan dalam penelitian ini terdiri dari beberapa tahapan, yaitu tahap pengumpulan data, analisis kebutuhan dan perancangan produk multimedia. Untuk mengimplementasikan aplikasi pengenalan bahasa Arab dan Inggris maka akan dibuat produk multimedia menggunakan metode Luther-Sutopo dengan tahapantahapan yang terdapat pada gambar 1 .

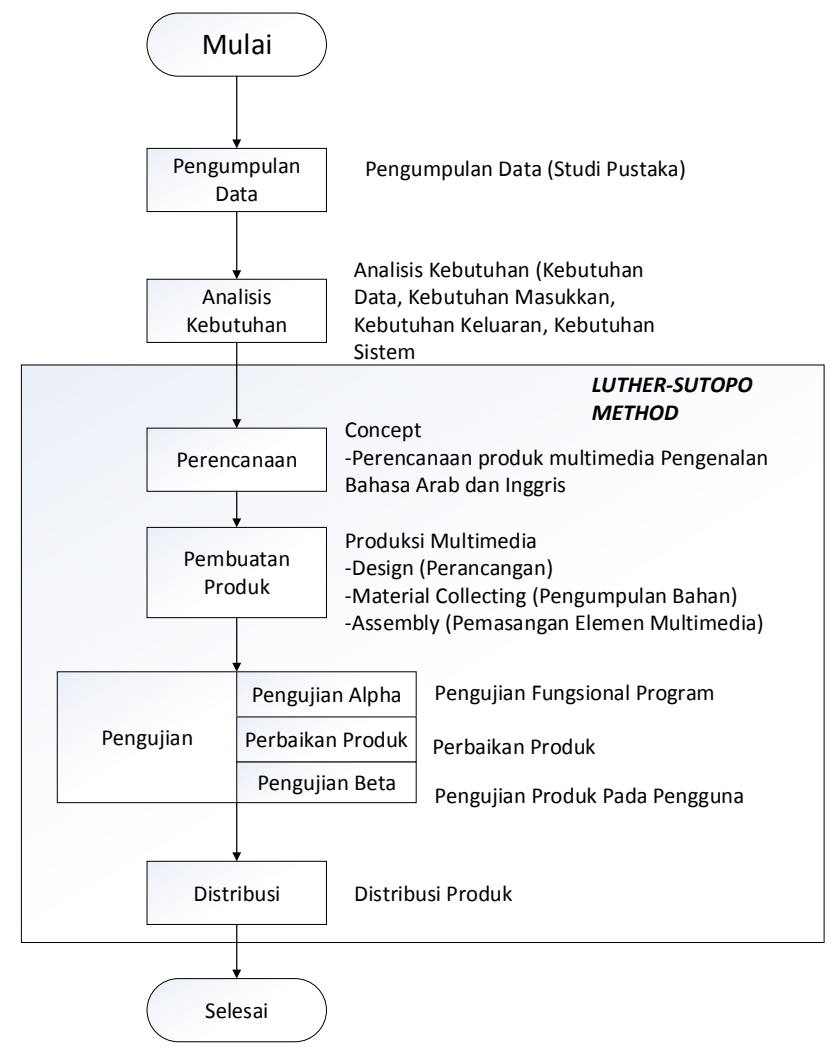

Gambar 1. Flowchart metode penelitian.

\section{A. PENGUMPULAN DATA}

Pengumpulan data biasanya diawali dengan studi pustaka, dimulai dari pengumpulan informasi dan bahanbahan dari buku yang mendukung penelitian ini. Dengan mengumpulkan informasi yang berhubungan dengan masalah penelitian informasi-informasi tersebut dapat diperoleh melalui peninjau pada buku yang relevan dan konsultasi dengan para ahli.

\section{B. ANALISIS KEBUTUHAN SISTEM}

Analisis kebutuhan adalah pernyataan tentang apa yang harus dikerjakan oleh sistem, dan karakteristik seperti apa yang harus dimiliki sistem. Penentuan kebutuhan sistem merupakan langkah yang paling krusial pada tahapan ini

\section{PERANCANGAN PRODUK MULTIMEDIA LUTHER-SUTOPO}

Metode perancangan yang digunakan dalam penelitian ini menggunakan metode rekayasa perangkat lunak berbasis multimedia versi Luther-Sutopo, dimana untuk membuat suatu produk multimedia dengan menggunakan metode ini harus melalui enam tahapan yang dilakukan secara berurutan bisa dilihat pada gambar 2.

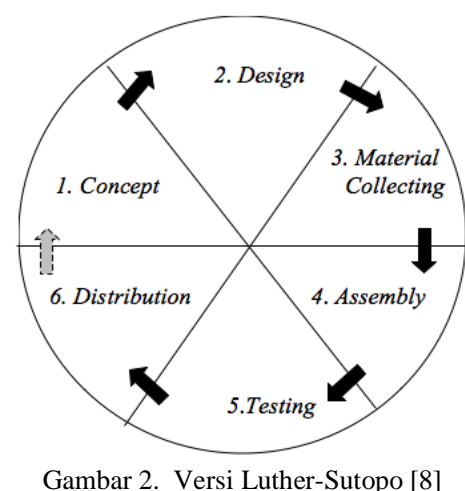

1. Konsep (Concept), untuk mendapatkan konsep awal dan ide pembangunan aplikasi berbasis multimedia ini, akan dilakukan pengumpulan data terlebih dahulu yang berhubungan dengan proses pembangunan produk multimedia ini.

2. Perancangan (Design), adalah merupakan tahapan dari pembuatan spesifikasi mengenai arsitektur tampilan, dan kebutuhan. Pada tahapan perancangan ini akan dibuat rancangan dari setiap scene atau frame menggunakan storyboard singkat dan lengkap.

3. Pengumpulan Bahan (Material Collecting), adalah tahapan dimana pengumpulan bahan yang sesuai dengan kebutuhan dilakukan. Pada tahapan ini dapat dikerjakan secara paralel dengan tahap Assembly. Pada beberapa kasus, tahap Material Collecting dan tahap Assembly dikerjakan secara linier tidak paralel.

4. Pemasangan (Assembly), adalah tahapan dimana semua objek atau bahan multimedia dibuat. Pembuatan produk multimedia dilakukan didasarkan pada tahapan design.

5. Pengujian (Testing) adalah tahapan percobaan dengan cara menjalankan aplikasi dan memeriksanya apakah ada kesalahan bug error atau tidak atau sudah berjalan secara fungsional. Tahapan pertama adalah pengujian alpha yang dilakukan oleh developer atau pembuatnya. Setelah selesai dari pengujian alpha akan dilakukan pengujian beta dengan melibatkan pengguna

6. Distribusi (Distribution) Pada tahapan ini, aplikasi atau produk akan disimpan dalam suatu media penyimpanan di internet. Jika media penyimpanan internet tidak mendukung bagi pangguna, adapun 
cara yang kedua yaitu dengan mengirim langsung antar ponsel android menggunakan media bluetooth.

\section{RENCANA PENGUJIAN (ALPHA TEST)}

Rencana pengujian alpha test dilakukan untuk menguji fungsi apakah navigasi bisa berjalan sesuai dengan yang diinginkan. Rencana pengujian alpha yang akan dilakukan bisa dilihat pada tabel 1 .

Tabel 1 Tabel Rencana pengujian alpha

\begin{tabular}{|c|c|c|}
\hline No & Pengujian & Hasil yang diharapkan \\
\hline 1 & $\begin{array}{l}\text { Tombol } \\
\text { Kamus }\end{array}$ & $\begin{array}{l}\text { Apabila di klik akan pindah ke } \\
\text { scene menu materi kamus }\end{array}$ \\
\hline 2 & $\begin{array}{l}\text { Tombol } \\
\text { Kuis }\end{array}$ & $\begin{array}{l}\text { Apabila di klik akan pindah ke } \\
\text { scene latihan pilihan ganda }\end{array}$ \\
\hline 3 & $\begin{array}{l}\text { Tombol } \\
\text { Tentang }\end{array}$ & $\begin{array}{l}\text { Apabila di klik akan pindah ke } \\
\text { scene informasi pembuat }\end{array}$ \\
\hline 4 & $\begin{array}{l}\text { Tombol } \\
\text { Keluar }\end{array}$ & $\begin{array}{l}\text { Apabila di klik menampilkan } \\
\text { pilihan ya atau tidak }\end{array}$ \\
\hline 5 & $\begin{array}{l}\text { Tombol } \\
\text { Alam } \\
\text { Semesta }\end{array}$ & $\begin{array}{l}\text { Apabila di klik akan pindah ke } \\
\text { scene materi alam semesta }\end{array}$ \\
\hline 6 & $\begin{array}{l}\text { Tombol } \\
\text { Alat Tulis }\end{array}$ & $\begin{array}{l}\text { Apabila di klik akan pindah ke } \\
\text { scene materi alat tulis }\end{array}$ \\
\hline 7 & $\begin{array}{l}\text { Tombol } \\
\text { Anggota } \\
\text { Tubuh }\end{array}$ & $\begin{array}{l}\text { Apabila di klik akan pindah ke } \\
\text { scene materi anggota tubuh }\end{array}$ \\
\hline 8 & $\begin{array}{l}\text { Tombol } \\
\text { Angka }\end{array}$ & $\begin{array}{l}\text { Apabila di klik akan pindah ke } \\
\text { scene materi angka }\end{array}$ \\
\hline 9 & $\begin{array}{l}\text { Tombol } \\
\text { Buah- } \\
\text { Buahan }\end{array}$ & $\begin{array}{l}\text { Apabila di klik akan pindah ke } \\
\text { scene materi buah-buahan }\end{array}$ \\
\hline 10 & $\begin{array}{l}\text { Tombol } \\
\text { Hewan }\end{array}$ & $\begin{array}{l}\text { Apabila di klik akan pindah ke } \\
\text { scene materi hewan }\end{array}$ \\
\hline 11 & $\begin{array}{l}\text { Tombol } \\
\text { Jenis } \\
\text { Kendaraan }\end{array}$ & $\begin{array}{l}\text { Apabila di klik akan pindah ke } \\
\text { scene materi kendaraan }\end{array}$ \\
\hline 12 & $\begin{array}{l}\text { Tombol } \\
\text { Nama Hari }\end{array}$ & $\begin{array}{l}\text { Apabila di klik akan pindah ke } \\
\text { scene nama hari }\end{array}$ \\
\hline 13 & $\begin{array}{l}\text { Tombol } \\
\text { Next }\end{array}$ & $\begin{array}{l}\text { Apabila di klik akan kembali ke } \\
\text { frame berikutnya }\end{array}$ \\
\hline 14 & $\begin{array}{l}\text { Tombol } \\
\text { Prev }\end{array}$ & $\begin{array}{l}\text { Apabila di klik akan kembali ke } \\
\text { frame sebelumnya }\end{array}$ \\
\hline
\end{tabular}

\section{E. RENCANA PENGUJIAN LAPANGAN (BETA TEST)}

Rencana pengujian beta test ini dilakukan untuk mengetahui apakah aplikasi yang dibuat sudah layak untuk digunakan dan didistribusikan. dalam pengujian beta ini akan dilakukan dengan memberikan kuesioner dengan penentuan jumlah responden yang akan dilakukan pada tahapan ini adalah kurang dari 100 populasi yaitu 10 sampai 30 responden yang melibatkan diantaranya staff pengajar taman kanak-kanak, mahasiswa, siswa SMP dan SD.

Penentuan jumlah responden berkenaan dengan ukuran dari jumlah populasi yang ada [9] mengungkapkan apabila jumlah subjek atau populasi kurang dari 100, akan lebih baik diambil semua sehingga penelitiannya merupakan penelitian populasi. Akan tetapi apabila jumlahnya terlalu banyak, bisa diambil antara 10\%-15\% atau 20\%-25\% atau lebih, tergantung dari:

1. Kemampuan peneliti dilihat dari waktu, tenaga, dan dana.

2. Sempit luasnya wilayah pengamatan dari setiap subjek karena hal ini menyangkut banyak sedikitnya data.

3. Besar kecilnya resiko yang ditanggung oleh peneliti.

Butir-butir kuisioner yang mengacu pada pengujian ini hanya menyangkut aspek fungsionalitas sistem dan output yang dihasilkan diantaranya adalah antarmuka, cara pengoperasian, isi atau materi, manfaat, dan pengembangan. Tabel aspek dan pertanyaan pada kuisioner yang akan dibuat dapat dilihat pada tabel 2 .

Tabel 2 Tabel Butir Kuisioner.

\begin{tabular}{|c|c|c|}
\hline No & Aspek & Pertanyaan \\
\hline 1. & Antarmuka & $\begin{array}{l}\text { 1. Apakah aspek visual seperti } \\
\text { teks, gambar, animasi, } \\
\text { background, serta aspek audio } \\
\text { (suara) sudah sesuai? } \\
\text { 2. Apakah antarmuka atau } \\
\text { tampilan aplikasi ini sudah } \\
\text { bagus? } \\
\text { 3. Apakah ketetapan warna, } \\
\text { ukuran tulisan dan tampilan } \\
\text { pesan dialog sudah sesuai? }\end{array}$ \\
\hline 2 & $\begin{array}{l}\text { Cara } \\
\text { Pengoperasian }\end{array}$ & $\begin{array}{l}\text { 1. Apakah aplikasi ini mudah } \\
\text { digunakan atau dioperasikan? } \\
\text { 2. Apakah tombol dan navigasi } \\
\text { yang ada mudah di pahami dan } \\
\text { mudah dikontrol? } \\
\text { 3. Apakah tombol perpindahan } \\
\text { dan navigasi ke halaman lain } \\
\text { yang dituju dalam aplikasi ini } \\
\text { sudah benar dan sesuai? }\end{array}$ \\
\hline 3. & Isi atau Materi & $\begin{array}{l}\text { 1. Apakah materi yang disajikan } \\
\text { sesuai dengan sumber lain } \\
\text { yang membahas materi } \\
\text { serupa? }\end{array}$ \\
\hline
\end{tabular}

2. Apakah materi yang disajikan mudah untuk dipahami?

3. Apakah materi yang disajikan dalam aplikasi dapat diterima dengan jelas?

4. Manfaat 1. Apakah aplikasi ini sangat bermanfaat?

2. Apakah penyampaian materi pada aplikasi ini sangat menarik dan dapat memotivasi pengguna untuk belajar?

3. Apakah penyajian informasi pada aplikasi ini sangat praktis untuk efisiensi waktu dari pada buku dan sumber lainya? 


\begin{tabular}{|c|c|c|}
\hline No & Aspek & Pertanyaan \\
\hline \multirow[t]{3}{*}{5.} & Pengembangan & $\begin{array}{l}\text { 1. Apakah aplikasi ini perlu atau } \\
\text { dapat dikembangkan lagi? }\end{array}$ \\
\hline & & $\begin{array}{l}\text { 2. Apakah aplikasi ini sudah } \\
\text { bagus tidak perlu untuk } \\
\text { dikembangkan lagi? }\end{array}$ \\
\hline & & $\begin{array}{l}\text { 3. Apakah aplikasi ini layak } \\
\text { untuk dipublikasikan? }\end{array}$ \\
\hline
\end{tabular}

Berdasarkan data dari hasil kuesioner tersebut, dapat dicari presentase masing-masing jawaban dengan menggunakan rumus 1 .

Rumus 1:

$$
Y=P / Q * 100 \%
$$

Keterangan :

$\mathrm{P}=$ Banyaknya jawaban responden tiap soal

$\mathrm{Q}=$ Jumlah Responden

$\mathrm{Y}=$ Nilai Presentase

Untuk menentukan kategori tingkat validitas multimedia interaktif, digunakan skala pengukuran rating scale. Interpretasi tingkat validitas tersebut bisa dilihat pada tabel 3 .

\begin{tabular}{ll}
\multicolumn{2}{c}{ Tabel 3 Kategori Tingkat Validitas } \\
\hline Presentase & Interpretasi \\
\hline $0-25$ & Tidak Layak \\
$25-50$ & Kurang Layak \\
$50-75$ & Layak \\
$75-100$ & Sangat Layak \\
\hline
\end{tabular}

\section{IV.HASIL DAN PEMBAHASAN}

\section{A. PENGUMPULAN DATA}

Tahapan ini dilakukan dengan studi pustaka, studi pustaka dilakukan dengan cara mengumpulkan dan mempelajari data-data yang berhubungan dengan penelitian ini, seperti teori-teori dasar multimedia dan metode pengembangannya, serta teori yang digunakan sebagai bahan untuk proses pembangunan aplikasi ini dari berbagai media seperti buku dan internet. Data yang dibutuhkan dalam pembuatan aplikasi ini berupa materi tentang pengenalan dasar bahasa Inggris dan bahasa Arab untuk anak-anak, dan materi pembelajaran yang akan disampaikan ada delapan, yaitu alat tulis, anggota tubuh, angka, buah-buahan, bulan, hari, hewan, transportasi.

\section{B. ANALISIS KEBUTUHAN SISTEM}

Kebutuhan perangkat mobile untuk menjalankan aplikasi pengenalan bahasa Arab dan Inggris dapat dilihat pada tabel 4.

Tabel 4. Spesifikasi Perangkat Mobile

\begin{tabular}{|c|c|c|}
\hline No & Nama Komponen & Spesifikasi \\
\hline 1 & Sistem Operasi & $\begin{array}{l}\text { Google Android } 4.2 \text { (Jelly } \\
\text { Bean) }\end{array}$ \\
\hline 2 & Processor & $\begin{array}{l}\text { Dual Core } 1 \mathrm{GHz} \\
\text { Broadcom BCM21664 }\end{array}$ \\
\hline 3 & Memory (RAM) & $R A M 1 G B$ \\
\hline 4 & Layar & TFT 4" dengan Resolusi \\
\hline
\end{tabular}

$480 x 800 p x$

\section{IMPLEMENTASI PRODUK MULTIMEDIA}

1. Konsep (Concept), hasil tahapan ini dapat dilihat pada tabel 5 yang merupakan konsep dari aplikasi yang dibangun.

Tabel 5. Konsep Aplikasi pengenalan bahasa Arab

\begin{tabular}{|l|l|}
\hline Judul & $\begin{array}{l}\text { Aplikasi Pengenalan Bahasa Arab } \\
\text { dan Inggris Berbasis Android }\end{array}$ \\
\hline Pengguna & Mulai dari usia 5 tahun ke atas. \\
\hline Durasi & Tidak terbatas (unlimited) \\
\hline Image & $\begin{array}{l}\text { Format *.png, *.jpg dan gambar } \\
\text { bertipe vektor yang dibuat sebagai } \\
\text { image dan animasi }\end{array}$ \\
\hline Animasi & $\begin{array}{l}\text { Vocal dan instrument dengan format } \\
\text { *wav dan *mp3 }\end{array}$ \\
\hline Interaktivitas & $\begin{array}{l}\text { Animasi 2D menggunakan feature } \\
\text { motion tween pada adobe flash cc }\end{array}$ \\
& $\begin{array}{l}\text { Tombol untuk perpindahan dari satu } \\
\text { Frame atau Scene ke Scene lain, } \\
\text { untuk kembali ke menu utama, dan } \\
\text { tombol "X" kembali ke scene } \\
\text { sebelumnya, tombol next lanjut ke } \\
\text { frame selanjutnya, tombol prev } \\
\text { kembali ke frame sebelumnya dan } \\
\text { tombol bendera untuk mengeluarkan } \\
\text { suara dari materi dan tombol keluar } \\
\text { untuk menutup aplikasi. }\end{array}$ \\
\hline
\end{tabular}

2. Perancangan (Design), hasil perancangan desain pada tahapan ini dapat dilihat pada tabel 6 .

Tabel 6. Storyboard Singkat

\begin{tabular}{|c|c|c|}
\hline Scene 1 & : & Merupakan scene Intro opening \\
\hline Scene 2 & : & $\begin{array}{l}\text { Merupakan Scene menu utama } \\
\text { yang berisi Scene tampilan } \\
\text { pilihan menu dari aplikasi } \\
\text { pengenalan bahasa Arab dan } \\
\text { Inggris }\end{array}$ \\
\hline Scene 3 & $:$ & $\begin{array}{l}\text { Merupakan Scene materi kamus } \\
\text { yang berisi Scene-Scene tentang } \\
\text { materi aplikasi pengenalan } \\
\text { bahasa Arab dan Inggris. }\end{array}$ \\
\hline Scene 4 & $:$ & $\begin{array}{l}\text { Merupakan scene latihan quiz } \\
\text { dimana dalam latihan ini } \\
\text { pengguna akan di uji daya } \\
\text { pengetahuan dan ingatannya. }\end{array}$ \\
\hline Scene 5 & $:$ & $\begin{array}{l}\text { Merupakan scene tentang yang } \\
\text { berisi beberapa informasi } \\
\text { pembuat aplikasi }\end{array}$ \\
\hline Scene 6 & : & $\begin{array}{l}\text { Merupakan scene materi alam } \\
\text { semesta }\end{array}$ \\
\hline Scene 7 & $:$ & Merupakan scene materi alat tulis \\
\hline
\end{tabular}




\begin{tabular}{|lll|}
\hline Scene $8:$ & $\begin{array}{l}\text { Merupakan scene materi anggota } \\
\text { tubuh }\end{array}$ \\
\hline Scene $9:$ & Merupakan scene materi angka \\
\hline Scene $10:$ & $\begin{array}{l}\text { Merupakan scene materi buah- } \\
\text { buahan }\end{array}$ \\
\hline Scene 11 : & Merupakan scene materi hewan \\
\hline Scene 12 : & $\begin{array}{l}\text { Merupakan scene materi jenis } \\
\text { kendaraan }\end{array}$ \\
\hline Scene 13 : & $\begin{array}{l}\text { Merupakan scene materi nama } \\
\text { hari }\end{array}$ \\
\hline
\end{tabular}

3. Pengumpulan Bahan (Material Collecting), dalam pembuatan aplikasi ini bahan dikumpulkan dan ada yang dibuat sendiri menggunakan Adobe Photoshop CC dan Adobe Illustrator $C C$, sedangkan untuk gambar materimateri aplikasi di ambil dari internet dari situs freepik, jenis tulisan atau font sp_aftershock, animasi menggunakan feature motion tween dari Adobe Flash CC, dan suara materi didapat dari hasil perekaman dari suara Helmalia Fatimatu Azzahra menggunakan ponsel, yang kemudian dilakukan proses editing menggunakan Audacity dengan format .mp3

4. Pemasangan (Assembly), proses pemasangan menggunakan bahasa pemrograman ActionScript 3.0 yang merupakan bahasa pemrograman dalam Adobe Flash Professional CC. Adapun hasil pemasangan pada tahap ini dapat dilihat pada gambar 3 sampai gambar 6 .

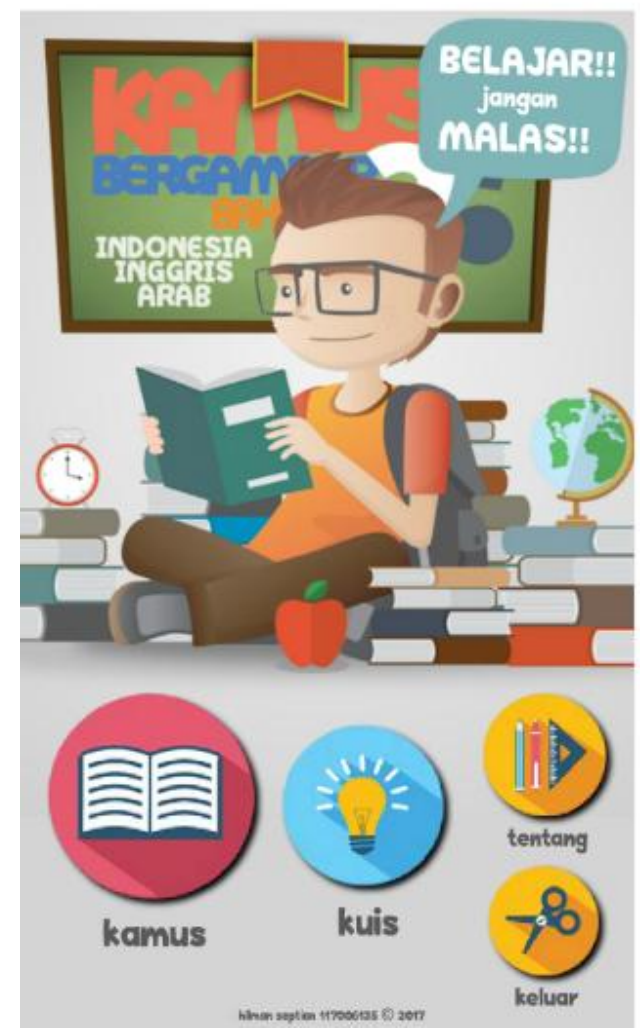

Gambar 3. Menu Utama

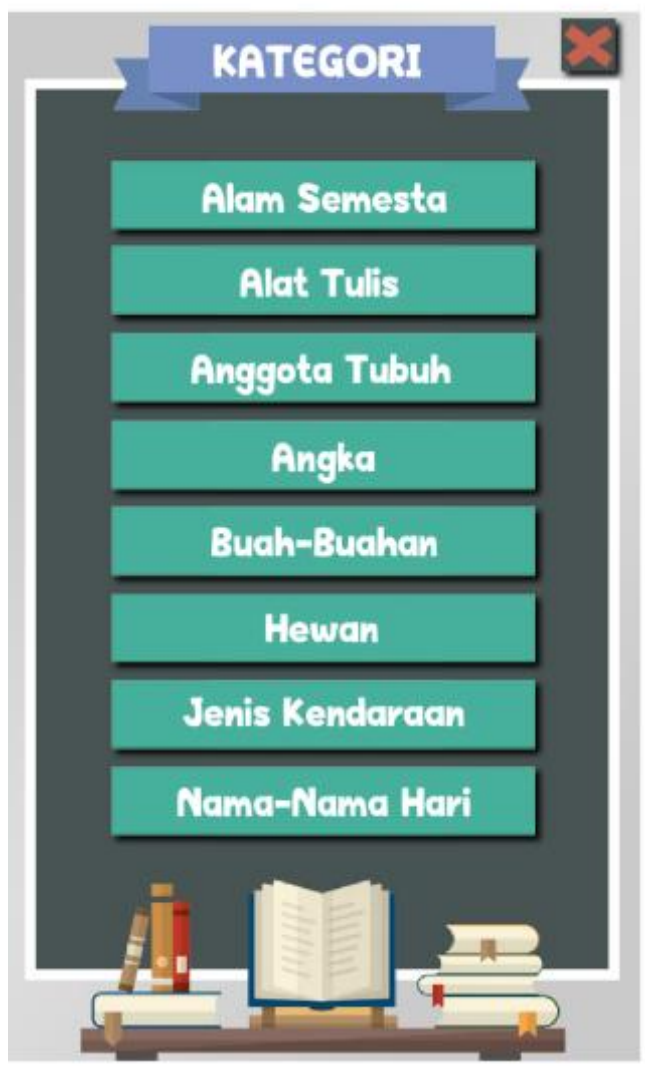

Gambar 4. Menu Materi

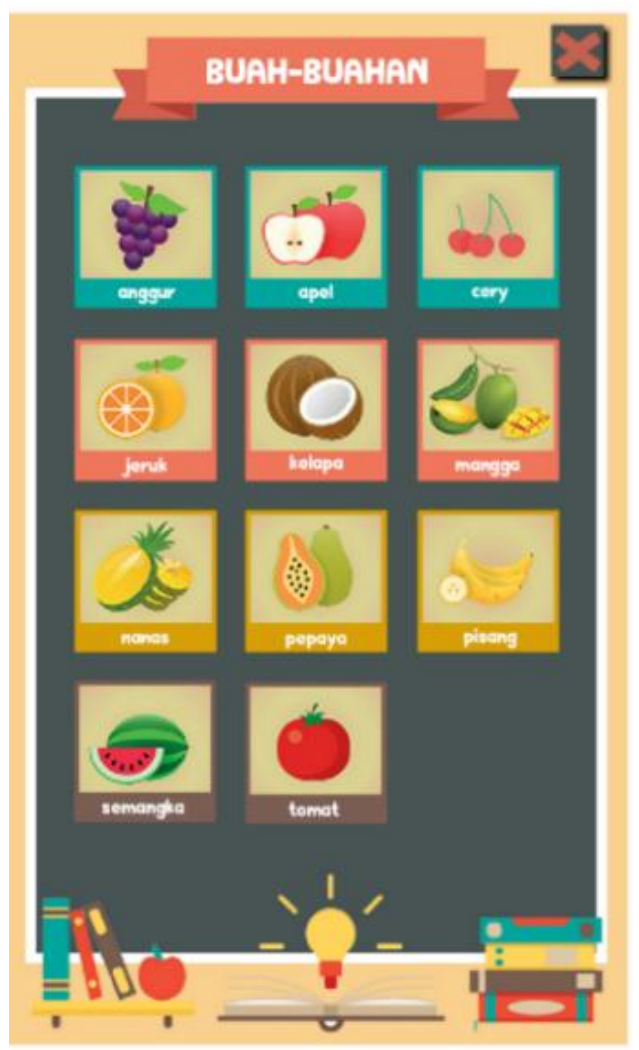


Gambar 5. Sub menu buah-buahan

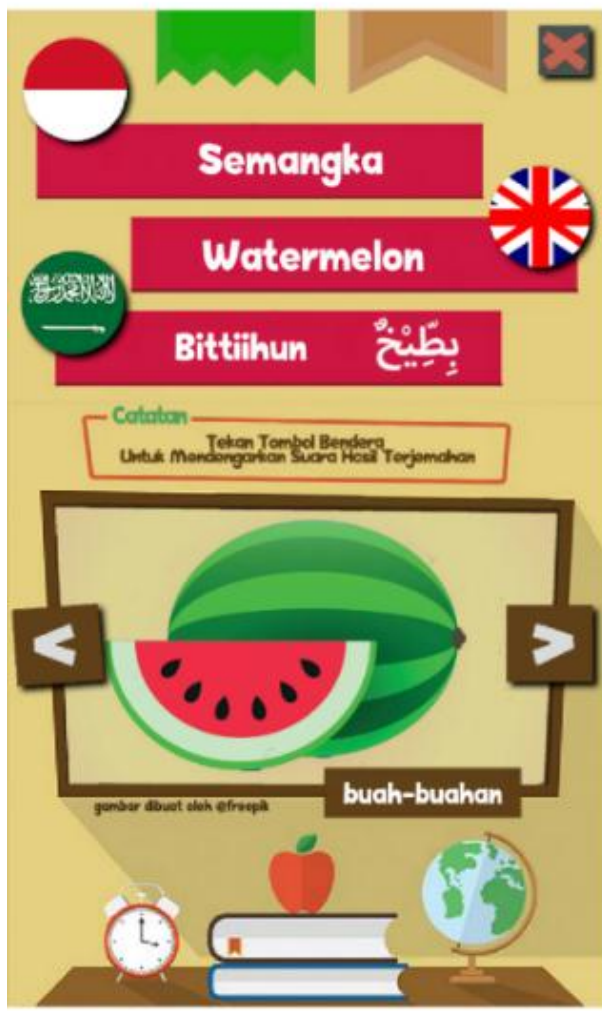

Gambar 6. Materi Buah-buahan

5. Pengujian (Testing), pengujian yang dilakukan adalah pengujian alpha dan pengujian beta.

a) Pengujian Alpha

Pengujian alpha dilakukan setelah produk multimedia selesai dibuat sampai ke tahap pemasangan (assembly), pengujian alpha ini dilakukan oleh pembuat atau lingkungan pembuatnya sendiri dengan tujuan untuk menguji fungsi apakah navigasi bisa berjalan sesuai dengan yang di inginkan. Berdasarkan hasil pengujian yang telah dilakukan, maka didapat hasil bahwa setiap navigasi berjalan baik dan sesuai dengan yang diharapkan.

b) Pengujian Beta

Pengujian beta dilakukan oleh pengguna produk setelah pengujian alpha dilakukan, Pengujian beta dilakukan dengan melibatkan 30 orang responden. Dengan pertanyaan yang diberikan adalah 15 soal. Masing-masing jawaban pada setiap pertanyaan dihitung nilai presentasenya menggunakan rumus 1 . Hasil dari pengujian beta yang telah dilakukan, maka didapat hasil kuesioner pada tabel 7 .

Tabel 7. Hasil Pengujian Beta

\begin{tabular}{ccc}
\hline Soal & Jawaban (\%) & Aspek (\%) \\
\hline 1 & 90 & Antarmuka
\end{tabular}

\begin{tabular}{ccc}
\hline Soal & Jawaban $(\%)$ & Aspek (\%) \\
\hline 2 & 93,34 & $276.68 / 3=92.22$ \\
3 & 93,34 & \\
4 & 86,67 & Pengoprasian \\
5 & 90 & $273.34 / 3=91.11$ \\
6 & 96,67 & \\
7 & 90 & Materi \\
8 & 100 & $286.67 / 3=95.55$ \\
9 & 96,67 & \\
10 & 100 & Manfaat \\
11 & 83,33 & $270 / 3=90$ \\
12 & 86,67 & \\
13 & 100 & Pengembangan \\
14 & 10 & $200 / 3=66.66$ \\
15 & 90 & \\
\hline Jumlah & $1306 / 15=87,11$ & \\
\hline
\end{tabular}

Berdasarkan hasil yang diperoleh pada tabel 7 hasil dari pengujian beta, maka didapat jumlah persentase jawaban setelah dibagi dengan 15 jumlah pertanyaan pada kuesioner yaitu $87,11 \%$, dengan melihat kembali tabel kategori tingkat validitas pada tabel 3 maka dapat disimpulkan bahwa aplikasi pengenalan bahasa Arab dan Inggris ini memiliki interpretasi 'Sangat Layak' sehingga dapat dikatakan aplikasi ini layak digunakan dan didistribusikan.

6. Distribusi (Distribution), aplikasi pengenalan bahasa Arab dan Inggris ini memiliki ukuran file mentah sebesar 36,6 MB dan ukuran file setelah build *.apk untuk di install pada perangkat android adalah 12,5 MB, adapun alokasi memory RAM saat aplikasi dijalankan pada perangkat android adalah sebesar $53 \mathrm{MB}$. Setelah produk multimedia ini selesai dibangun dan telah melalui tahap pengujian. maka langkah selanjutnya adalah melakukan distribusi produk. Pendistribusian yang dilakukan adalah dengan cara mengupload kedalam media internet yaitu google drive yang menghasilkan sebuah link download berikut (https://goo.gl/3sUip5) kemudian link tersebut dibagikan kepada pengguna menggunakan blog (ngabaris.blogspot.co.id) dan sosial media, adapun cara kedua yaitu dengan cara mengirimnya langsung antar ponsel android menggunakan media Bluetooth atau media transfer file lainya.

\section{KELEBIHAN DAN KEKURANGAN}

Kelebihan aplikasi ini adalah sebagai berikut:

1. Materi-materi yang disampaikan dalam aplikasi ini dibuat dengan memperhatikan aspek visual seperti gambar, animasi, warna, background, dan suara yang disesuaikan untuk anak-anak khusunya usia 5-8 tahun sehingga menjadi media pembelajaran yang tidak hanya edukatif dan interaktif, namun juga dapat menghibur. 
2. Penyampaian informasi dalam aplikasi ini juga menggunakan instruksi narator dari tiap interaksi tombol sehingga anak-anak usia 5 tahun yang belum lancar membaca juga dapat mempelajari materi dengan mengikuti instruksi-instruksi tersebut.

3. Dalam aplikasi ini juga terdapat Quiz, tujuanya agar pengguna bisa menguji pengetahuan dan ingatannya.

Kekurangan aplikasi ini adalah sebagai berikut:

1. Suara yang dihasilkan kurang jernih, karena pada proses perekaman suara dilakukan menggunakan ponsel.

2. Resolusi gambar lebih responsible pada ukuran 480x800 pixel.

\section{KESIMPULAN DAN SARAN}

\section{A. KESIMPULAN}

Berdasarkan hasil pembahasan dan implementasi dalam laporan tugas akhir ini telah dibangun sebuah produk multimedia pengenalan bahasa Arab dan Inggris berbasis multimedia pada sistem operasi android yang dapat menjadi salah satu solusi atau alternatif sebagai media pembelajaran yang interaktif dan praktis dengan pendekatan rekayasa produk multimedia menurut konsep Luther-Sutopo dengan tahapan concept, design, material collecting, assembly, testing dan distribution. Pembuatan produk multimedia ini menggunakan software Adobe Photoshop CC, Adobe Illustrator CC untuk editing gambar untuk pemasangan atau pembuatan pada aplikasi menggunakan Adobe Flash CC dengan bahasa pemrograman Action Script 3.0. Dari hasil kuesioner dengan nilai sebesar $87,11 \%$ maka dapat disimpulkan bahwa produk multimedia pengenalan bahasa Arab dan Inggris ini memiliki interpretasi 'Sangat Layak', sehingga dapat dikatakan aplikasi pengenalan bahasa Arab dan Inggris ini layak untuk digunakan dan di distribusikan.

\section{B. SARAN}

Beberapa saran untuk pengembangan aplikasi pengenalan belajar bahasa Arab ini sebagai berikut:

1. Menambahkan bahasa Inggris atau bahasa Arab sebagai default bahasa aplikasi.

2. Aplikasi ini diharapkan bisa mendukung di semua tipe layar perangkat mobile (responsive).

3. Melakukan perakaman aset untuk mengisi suara materi bahasa dilakukan di studio multimedia khusus.

4. Aspek terendah dari hasil kuisioner adalah aspek pengembangan, yang artinya masih perlu dikembangkan diantaranya penambahan fitur baru seperti penambahan bahasa baru dan penambahan materi.

\section{REFERENSI}

[1] "Operating System Market Share Worldwide," [Online]. Available: http://gs.statcounter.com/osmarket-share. [Accessed 0909 2017].

[2] D. Rosyada, Media Pembelajaran : Sebuah Pendekatan Baru, Jakarta: Gaung Persada Pers, 2008.

[3] A. Arsyad, Media Pembelajaran, Jakarta: PT Raja Grafindo Persada, 2002.

[4] T. Vaughan, Multimedia Making It Work, Sixth Edition, New York: McGraw-Hill Companies, 2004.

[5] I. Sommerville, Software Engineering 6th Edition, Lancaster: Addison Wesley Publishing, 2000.

[6] N. S. H, Pemrograman Aplikasi Mobile Smartphone dan Tablet PC berbasis Android, Bandung: Informatika, 2012.

[7] S. H. S, Mudah Membuat Aplikasi Android, Yogyakarta: Andi Offset, 2011.

[8] I. Binanto, Multimedia Digital Dasar Teori dan Pengembangannya, Yogyakarta: Andi Offset, 2010.

[9] S. Arikunto, Prosedur Penelitian, Suatu Pendekatan Praktik, Jakarta: Rineka Cipt, 2006. 